STUDI

FRANCESI

\section{Studi Francesi}

Rivista quadrimestrale fondata da Franco Simone

165 (LV | III) | 2011

LA RAPPRESENTAZIONE DELLA MADRE NELLA

LETTERATURA FRANCESE DEL NOVECENTO a cura di Dario Cecchetti e Michele Mastroianni

\title{
Stefania Cerrito, Le rommant de l'abbregement du siege de Troyes
}

\section{Maria Colombo Timelli}

\section{OpenEdition \\ Journals}

\section{Édition électronique}

URL : http://journals.openedition.org/studifrancesi/4931

DOI : 10.4000/studifrancesi.4931

ISSN : 2421-5856

\section{Éditeur}

Rosenberg \& Sellier

Édition imprimée

Date de publication : 1 décembre 2011

Pagination : 623-624

ISSN : 0039-2944

Référence électronique

Maria Colombo Timelli, «Stefania Cerrito, Le rommant de l'abbregement du siege de Troyes », Studi Francesi [En ligne], 165 (LV | III) | 2011, mis en ligne le 30 novembre 2015, consulté le 11 janvier 2021. URL : http://journals.openedition.org/studifrancesi/4931; DOI : https://doi.org/10.4000/studifrancesi. 4931

Ce document a été généré automatiquement le 11 janvier 2021.

\section{(†) $\odot$

Studi Francesi è distribuita con Licenza Creative Commons Attribuzione - Non commerciale - Non opere derivate 4.0 Internazionale. 


\title{
Stefania Cerrito, Le rommant de l'abbregement du siege de Troyes
}

\author{
Maria Colombo Timelli
}

\section{RÉFÉRENCE}

STEFANIA CERRITO, Le rommant de l'abbregement du siege de Troyes, Édition, étude linguistique et littéraire, Aix-en-Provence, Publications de l'Université de Provence, 2010 , pp. 360.

1 Dans la riche tradition médiévale centrée sur la matière de Troie, cet Abbregement anonyme, datable selon S.C. entre 1453 et 1467, fait figure d'exception: transmis par un manuscrit unique (Valenciennes, B.M., 461) appartenu à Philippe de Croÿ, le Rommant est en effet rédigé en vers à une époque où la littérature narrative s'exprime quasi entièrement en prose, et offre une sorte de synthèse de la guerre de Troie, précédée d'un récit détaillé de la conquête de la Toison d'or par Jason, un des mythes les plus vivants et les plus célèbres à la cour de Philippe le Bon. Si le mélange d'armes et d'amours promis dès le prologue (v. 21) ne surprend pas à une époque où ce sont les récits hybrides qui jouissent du plus grand succès, c'est justement la rédaction en couplets d'octosyllabes - le mètre traditionnellement réservé au roman - qui étonne, surtout si on la compare aux nombreuses rédactions en prose étudiées par Marc-René Jung ou aux productions originales bourguignonnes (Jason ou Recueil des histoires de Troie de Raoul Lefèvre, entre autres). L'auteur annonce une matiere tirée briefment (v. 16) d'un livre: sa source est le Roman de Troie de Benoît de Sainte-Maure, mais les quelque 30000 vers de Benoît sont réduits ici à 4700 ; loin d'être homogène, cette réduction se fait au prix de synthèses, suppressions d'épisodes, certes, mais aussi de reprises textuelles.

2 L'introduction comprend une description du manuscrit (pp. 11-21), une présentation du contexte historique (cour de Bourgogne et ordre chevaleresque de la Toison d'or, pp. 23-31), une étude linguistique (pp.33-46); l'analyse détaillée du texte (pp.33-56) interrompt quelque peu l'exposé, juste avant le chapitre substantiel consacré aux 
aspects littéraires et culturels qui permettent vraiment d'encadrer le Rommant (pp. 57-102). S.C. montre bien les rapports entre le texte de Benoît et la réécriture du $\mathrm{Xv}^{\mathrm{e}}$ siècle (tables aux pp. 67-70), pour approfondir ensuite les thèmes et les techniques, les personnages et les épisodes retenus. Son apport le plus original me semble être l'interprétation de l'œuvre: aux yeux de l'éditrice, qui produit bien des éléments à l'appui, s'établirait ici une parenté entre les Troyens et les Turcs, et en contrepartie entre les Grecs et les Bourguignons, ce qui expliquerait, d'une part, un portrait de Jason proche de celui de Philippe le Bon, d'autre part la justification de la destruction de Troie à l'époque où le Grand Duc rêvait encore de la possibilité d'une croisade qui délivrerait Constantinople.

3 Les critères pour l'établissement du texte sont exposés avec clarté (pp. 103-108). Le Rommant est édité avec soin (ne faudrait-on pas modifier la ponctuation à la fin du v. 954? «Et Thelamon, quant ce entent, / Si l'a en bonne garde mis, Mener li fist en son paÿs / Ainsi que cela on faisoit. / Läomedon se combatoit...», vv. 952-956); la numérotation continue des vers, qui semble de prime abord surcharger quelque peu la page, s'avère en réalité bien commode pour les renvois, tant dans les notes en fin de texte, destinées aux commentaires (pp. 228-239; l'apparat en bas de page concerne plutôt des questions codicologiques et métriques: le nombre des vers faux, hypermétriques surtout, est très élevé), que dans le glossaire et autres appareils complémentaires.

4 L'édition est complétée par une Table des noms propres (pp. 241-246) et par un Glossaire très soigné (pp. 247-331), où on entrevoit la formation française de Stefania Cerrito, qui a rédigé cette thèse sous la direction de May Plouzeau; exhaustif, il constitue un outil indispensable pour la compréhension d'un lexique qui - sans être trop profondément marqué par les traits du Nord et du Nord-Est - présente néanmoins quelques difficultés. Je me permets de signaler l'absence de la conjonction mais que (v. 767 par ex.), 'à condition que', 'pourvu que', ainsi que du sy dit d'antériorité («N’en rentreray en ces paÿs / Sy aray le toison conquis», affirme Jason aux vv. 127-128), pour lequel il faut renvoyer à Chr. Marchello-Nizia (Dire le vrai: l'adverbe «si» en français médiéval, Genève, 1985, pp.57-64); la locution tout en val (v. 918) aurait mérité une glose: 'précipitamment'.

5 La Table des proverbes (pp. 333-334) appelle quelques remarques: sauf erreur de ma part, S.C. n'a pas utilisé le Thesaurus Proverbiorum Medii Aevi, qui lui aurait certainement rendu quelques services, et sa liste doit être complétée, surtout parce qu'elle est censée contenir «les proverbes proprement dits, mais aussi [...] les expressions sentencieuses ou imagées»; pour les 1000 premiers vers, j'ajouterais au moins: «Laide chose est de manechier» (v. 232), à rapprocher de «an menacier n'a nul savoir» (Erec) et de «Trop peut on manacier, car c'est folie» (Proverbes ruraux), signalés dans TPMA, s.v. Drohen, n. 3, 4. Par ailleurs, l'expression «d'une escolle / Sont tous les hommes escollé» (vv. 378-379) est très proche de celle qui se lit dans le répertoire de G. Di Stefano (Toutes les herbes de la Saint-Jean, Montréal, Ceres, 1991), s.v. école: «avoir esté a une escole, avoir la même attitude, la même manière». De même, «on n'oüt pas les dieux tonnans» (v. 604), dont S.C. déclare qu'elle «n'apparaît pas dans les proverbes répertoriés» (sic, p. 333), n'est certes pas un proverbe au sens propre, mais une image des plus exploitées surtout dans les descriptions des rencontres armées, et elle est bien signalée par le même Di Stefano, s.v. Dieu.

La Bibliographie, très riche, suit une présentation raisonnée (pp. 335-356). 
7 Très bonne édition dans l'ensemble, elle met à la disposition des lecteurs une des œuvres les moins connues $d u x^{e}$ siècle, qui prouve encore le succès de la matière de Troie à l'extrême fin du Moyen Âge et sa grande variété. 